\title{
MOTION GRAPHICS E SEU PAPEL NA INTERFACE DO USUÁRIO
}

\author{
Guilherme Oliveira Pironi
}

Universidade do Oeste Paulista - UNOESTE, Pós Graduação EAD em Mídias Digitais Interativas, Presidente Prudente, SP. E-mail: guilhermeop@hotmail.com

\section{RESUMO}

Neste artigo serão discutidos conceitos, objetivos e a importância da interação entre usuário e interface digital e como a animação se faz presente assim como qual a sua real importância e intenção nessa relação com objetivo final de evidenciar seu valor positivo na experiência do usuário. Para realizar tal estudo demonstramos como vem sendo apontada a relação entre pessoas e dispositivos que se valem de interfaces digitais - também conceituadas e explicadas ao decorrer do texto - evidenciando como o sucesso de tal interação pode depender da forma como a interface foi projetada e de ferramentas presentes nesta que venham a auxiliar na usabilidade do produto como por exemplo o principal objeto de estudo desta pesquisa: as animações ou como retratadas para os fins deste artigo Motion Graphics, ou seja, imagens em movimento que devem acrescentar algo de positivo à interface digital e por consequência à experiência do usuário.

Palavras - chave: Interface; Interação; Design; Motion Graphics; Era digital.

\section{MOTION GRAPHICS AND IT'S ROLE IN USER INTERFACE}

\begin{abstract}
This article will discuss concepts, objectives and the importance of interaction between user and digital interface and how the animation is present as well as what their real importance and intent in this regard aiming to improve the user experience. To perform this study pointed to has been given the relationship between people and devices which use digital interfaces - also conceptualized and explained in the course of the text - showing how the success of such an interaction may depend on how the interface is designed and tools present in it that may help in the usability of the product such as the main object of study of this research: the animations or as portrayed for the purposes of this article Motion Graphics, ie moving images that should add something positive to the digital interface and therefore the user experience.
\end{abstract}

Keywords: Interface; Interaction; Design; Motion Graphics; Digital age. 


\section{INTRODUÇÃO}

É inegável que a cada dia que passa estamos mais ligados a nossos dispositivos eletrônicos sejam eles smartphones, tablets, notebooks e afins. Assim sendo atribui-se cada vez mais importância na forma como interagimos com tais objetos (sendo tal interação feita através de uma interface) ou seja, o mecanismo que faz com que ações executadas pelo usuário manipulem o funcionamento de um sistema virtual.

Podemos afirmar que esta é parte vital da experiência de usabilidade do usuário podendo tanto tornar sistemas complexos fáceis de operar quando bem desenvolvida quanto ter o efeito contrário se mal projetada, fazendo com que sistemas de operação supostamente simples se tornem de extrema dificuldade operacional para seus usuários.

Como ferramenta auxiliar na hora da interação entre usuário e interface podemos contar com alguns recursos inseridos pelo Designer de UI/UX ${ }^{1}$ como, por exemplo, o artifício que abordaremos neste artigo: a animação, chamada de Motion Graphics quando usada com a finalidade recém apresentada. Esta deve servir para chamar a atenção dos usuários para aspectos importantes de sua interação como: feedback ${ }^{2}$ de suas entradas de comando; maior fluidez em sua interação com a interface; destaque de elementos que sofreram ou possam sofrer alteração durante o uso do software; auxiliando o interator na descoberta de qual deve ser seu próximo passo dentro do sistema para navegar até o resultado desejado.

O objetivo dessa pesquisa é evidenciar o valor positivo do uso de Motion Graphics inseridos em uma interface digital a fim de guiar e melhorar a experiência de interação de usuários tornando esta mais fluída, fácil, agradável e com o mínimo de entradas de comando erradas durante sua interação.

\section{METODOLOGIA}

Para a realização do presente artigo foi feita uma pesquisa qualitativa de caráter descritivo e explicativo. Nesta perspectiva o levantamento de informações sobre a influência de animações em forma de Motion Graphics, objetivaram compreender o papel do mesmo na relação entre experiência do usuário e a interface que este opera.

Portanto, o procedimento metodológico utilizado constituiu-se em pesquisas bibliográficas. Deste modo, por meio do referencial bibliográfico, as informações relacionadas ao tema como: recomendações práticas no design de interface; tendências atuais no uso de dispositivos digitais; bem como a conceituação e exploração de origem foram abordadas e discutidas durante a pesquisa.

\section{RESULTADOS}

\subsection{Uso Das Novas Tecnologias: A Era Digital}

Quando pensamos em computador a primeira imagem que vem à nossa mente é a de uma máquina composta de um monitor de vídeo e um gabinete que poderiam facilmente ser alocados em qualquer residência, entretanto para as gerações atuais podemos considerar os smartphones como os novos computadores, afinal, estes executam a maioria das funções de um computador normal sem muita dificuldade contudo, para atingir este patamar de elevado desenvolvimento tecnológico nos dias atuais, foi necessário percorrer um longo caminho em tempos pretéritos.

Desenvolvidos na metade do século XX para fins militares os computadores constituíam-se em máquinas de grande porte, que necessitavam de grandes espaços físicos de instalação; situação que perdurou sem muitas mudanças até a década de 1980 quando, segundo TANENBAUM (2003), começou a ser possível fazer máquinas menores graças à criação dos

\footnotetext{
${ }^{1}$ Designer de UI/UX é aquele responsável pela interface (UI - User Interface, Interface do Usuário em inglês) e pela maneira como se dará a interação homem-sistema (UX - User Experience, Experiência do Usuário em inglês).

${ }^{2}$ Feedback é a reação do sistema a uma entrada do usuário (p.ex. ao tocar um botão este muda de cor).
} 
circuitos integrados em larga escala: chips contendo milhares de transistores em apenas um centímetro quadrado de silício. Cientes desse avanço empresas como IBM e Apple enxergaram uma oportunidade para trazer computadores para dentro das casas de pessoas comuns, surgiam então os primeiros PC (Personal Computer - Computador Pessoal em inglês).

A tarefa de fazer com que pessoas aderissem ao uso dessas máquinas não foi fácil, JOHNSON (2001) nos aponta que grande parte do mérito por essa adesão em massa aos dispositivos digitais deve-se ao design de interface e de interação: "A adoção generalizada da GUI operou uma mudança colossal no modo como os seres humanos e os computadores interagem, e expandiu enormemente a capacidade de usar os computadores" (JOHNSON, 2001, p. 25). Portanto, se os computadores pessoais ainda exigissem conhecimentos profundos e específicos para sua operação provavelmente a iniciativa teria sido um fracasso, já que ao se frustrar tentando realizar uma tarefa o usuário normalmente perde o interesse por esta. $\operatorname{KRUG}(2014$, p. 22) evidencia isso ao dizer que em um sistema bem planejado "uma pessoa com habilidade e experiência normais (ou até abaixo do normal) consegue descobrir como usar algo para cumprir uma tarefa sem mais esforço do que o necessário".

Sendo assim afirmamos que não é necessário apenas que o sistema tenha condições técnicas de realizar a tarefa, mas também que ele apresente a maneira de desempenhar tal feito de forma simples.

\subsection{Relação entre as novas tecnologias e seus usuários}

É fato que a maioria das pessoas vão se relacionar com algum dispositivo digital em algum ponto de sua vida, o que difere nessa situação é como essa relação vai acontecer e qual a impressão do usuário a partir disso, assim, caso ocorra uma frustração da parte do indivíduo ao tentar realizar uma interação com o objeto em questão (vinda da falta de conhecimento prévio para a operação ou por falha no Design de UI/UX do sistema) esta poderá acarretar uma impressão negativa por parte do usuário, prejudicando sua inclusão digital.

Tendo em vista que o domínio dos dispositivos digitais para consumo de mídia é inevitável, nasce a necessidade de facilitar a adaptação da sociedade a essa nova realidade e evitar experiências negativas por parte dos usuários, passo que pode ser alcançado aliando boas práticas do Design de UI/UX em conjunto com a familiarização no mundo digital desde o início da formação como colocado por RAMOS $(2014$, p. 46)

Em uma sociedade com desigualdade social como a que vivemos, a escola pública em alguns casos torna-se a única fonte de acesso às informações e aos recursos tecnológicos, das crianças de famílias da classe trabalhadora baixa. A esse respeito Pretto $(1999,104)$ vem afirmar que "em sociedades com desigualdades sociais como a brasileira, a escola deve passar a ter, também, a função de facilitar o acesso das comunidades carentes às novas tecnologias.".

Nesse contexto uma parte do problema seria resolvida, pois o jovem teria ao fim de sua formação escolar condições básicas para operar dispositivos digitais comuns, entretanto ainda é necessário levar em consideração que grande parte dos indivíduos demonstrando resistência quanto ao uso de tais tecnologias são sujeitos de elevada faixa etária com alguma dificuldade em operar sistemas que não sejam palpáveis e é nesse caso que voltamos a destacar a importância das boas práticas no Design de UI/UX nestes ambientes digitais.

Sendo assim o bom produto deve ser projetado para ensinar o usuário como se faz a operação durante o processo de realização da mesma, situação exemplificada por CHONG (2011, p. 135) ao dissertar sobre o uso de Motion Graphics em interfaces digitais, "não são enfeites para promover o desempenho da tecnologia contida, mas dicas cuidadosamente coreografadas que 
ajudam o usuário a navegar pelas funções e pela topologia virtual das informações.". Isto é, o próprio software deve ser o tutor.

\subsection{Motion Graphics e a Interface: Introduções aos Conceitos}

Não importa o dispositivo digital que abordemos, sejam eles smartphones, tablets, notebooks ou mesmo e-readers ${ }^{3}$ todos tem um ponto em comum: a interação com tais objetos ocorre por meio de uma Interface Gráfica de Usuário (GUI - Graphic User Interface) que atua interpretando o que é computado pelo software de maneira que este possa ser entendido e utilizado pelo usuário; JOHNSON (2001) ressalta essa importância ao afirmar que:

Um computador que nada faça além de manipular sequências de zeros e uns não passa de uma máquina de somar excepcionalmente ineficiente. Para que a mágica da revolução digital ocorra, um computador deve também representar-se a si mesmo ao usuário, numa linguagem que este compreenda. (JOHNSON, 2001, p. 24).

No contexto da importância da interface gráfica destaca-se Douglas Engelbart como um dos principais responsáveis por essa revolução na usabilidade dos computadores e por consequência dos smartphones e tablets ja que em 1968 ele idealizou a ideia das metáforas visuais na UI, mais tarde entendidas como esqueumorfismos: recurso onde características visuais dos objetos reais são transportadas para suas representações digitais, diminuindo a necessidade do conhecimento específico em informática para a interação em ambientes virtuais.

Por fim ao falar de interface é preciso introduzir também a interação sistema/usuário e as práticas do design de interação, pois, ambos estão intimamente ligados já que esta interação é percebida pelo usuário através da operação de elementos da interface.

O principal objetivo do Design de Interação nessa parceria é pensar cuidadosamente como o usuário vai se relacionar com determinada interface para que esta tenha sua manipulação simplificada ou como apontado por ROGERS et al $(2013$, p. 2) "[...] reduzir os aspectos negativos da experiência de usuário (p.ex., frustração, aborrecimento) e ao mesmo tempo melhorar os positivos (p.ex., divertimento, compromisso)" quer dizer, antecipar as ações do interator ao projetar o sistema para que no momento da operação tudo corra como o esperado.

\subsection{Conceituando e diferenciando Animação Digital e Motion Graphics}

Introduzida por cineastas no início do século XX a animação se tornou uma das formas mais populares de desenvolvimento de uma narrativa, em especial por sua liberdade e facilidade na arte de transmitir ideias.

Desde então esta arte foi se ramificando e sendo aplicada não só com a função de entreter como foi feito pelo cinema, contudo REATEGUI (2007) aponta que ela também pode ser aplicada como ferramenta de explicação, organização e representação de ideias e conceitos ganhando através destas qualidades aliadas a técnicas que anteriormente faziam parte apenas do design gráfico um novo nome, Motion Graphics:

O design gráfico foi por muitos anos algo totalmente distinto da animação. John Whitney Sr. e Saul Bass anteciparam o advento do motion graphic projetado na tela, que combina preocupações do design tradicional: o uso de tipos, distinção estética, signos de comunicação eficientes e a capacidade de formas se moverem e se transformarem. (CHONG, 2011, p. 35).

\footnotetext{
${ }^{3}$ E-readers são leitores digitais que através de uma tinta eletrônica simulam a experiência de ler um livro comum em uma tela de LCD.
} 
Desta maneira foi adotado o uso do termo Motion Graphics nesta pesquisa porque este se alinha com o objetivo de analisar animações pensadas cautelosamente como parte da experiência do interator com a interface.

\section{DISCUSSÕES}

\subsection{Motion Graphics como parte da interface}

Os resultados evidenciaram que para ocorrer o avanço da tecnologia e dos dispositivos eletrônicos com interface digital mostra-se necessário também que as formas de interação homem-máquina sejam aprimoradas e para isso é fundamenal que o designer leve em consideração todas as ferramentas a sua disposição para criar a melhor experiência possível para o usuário, entre elas esta a animação em forma de Motion Graphics como evidenciado por CHONG (2011, p. 135):

O uso de tecnicas de animação no projeto de um telefone não é uma associação imediata para a maioria das pessoas, incluindo os animadores. Contudo, à medida que a variedade de funções disponiveis para o usuário aumenta, a interface entre a pessoa e o equipamento precisa se desenvolver.

Na mesma linha de raciocínio o guia Material Motion (2016) para o uso de Motion Graphics em interfaces digitais desenvolvido pela Google ${ }^{4}$ diz que as animações relacionadas à UI/UX (User Interface/User Experience - Interface do Usuário/Experiência do Usuário) devem se ater a funções específicas que adicionem algo substancial à experiência do interator e mostrar consistência em sua aplicação.

Continuando a análise das sugestões de tal guia percebemos que o uso dessas animações vem com a intenção de facilitar e ensinar ao usuário o funcionamento do sistema de maneira simples como, por exemplo, o uso de Motion Graphics para sugerir onde o usuário deve focar sua atenção, mostrar relação espacial e hierárquica entre elementos da interface e algumas vezes entreter o usuário enquanto o sistema executa alguma ação como carregar o conteúdo que será apresentado em seguida; técnicas estas já validadas por teóricos como MAYER (2009) onde podemos enfatizar seu Princípio da Sinalização no qual o autor sugere que as pessoas aprendem melhor quando algo destaca quais os principais pontos da experiência - reafirmando que a animação pode sugerir o elemento que precisa de foco para melhorar a experiência do usuário.

\section{CONCLUSÃO}

Analisando os tópicos apresentados ao decorrer deste artigo concluímos que na sociedade atual se faz cada vez mais necessária a interação entre humano e interface digital uma vez que, se este intercâmbio não ocorrer, todas as informações contidas no ciberespaço não passarão de códigos ininteligíveis para leigos em linguagem de programação para computador.

Dessa forma se faz necessário que seja dada atenção especial ao Design de UI/UX de um projeto e, portanto, o uso de recursos como Motion Graphics na interface serve o propósito de tornar a interação mais fácil, natural e fluída ao guiar o usuário através do uso do movimento em elementos específicos na arquitetura digital porém se atendo à naturalidade destes movimentos aumentando assim a familiaridade do usuário com a situação.

Uma vez creditados os bons resultados do uso de Motion Graphics na interface devemos então ressaltar que estes são atingidos apenas se houver bom uso da ferramenta aplicando-se alguns dos princípios de design, por exemplo, os apontados por ROGERS et al $(2013$, p.18) ao afirmar que no desenvolvimento de uma interface é necessário focar nas questões referentes às

\footnotetext{
${ }^{4}$ Google é uma empresa do ramo de tecnologia responsável pelo desenvolvimento do sistema operacional móvel Android para o qual as guias de design citadas foram escritas.
} 
suas metas de usabilidade que são metas propostas que garantem a eficácia, eficiência, segurança, utilidade, facilidade na aprendizagem do uso e facilidade na memorização de como usar.

Assim, mais importante do que apenas a bela forma é o casamento desta com a funcionalidade para aprimorar, simplificar e facilitar o quanto possível a experiência de interação entre usuário e interface.

\section{REFERÊNCIAS}

CHONG, Andrew. Animação Digital. Porto Alegre: Bookman, 2011.

GOOGLE. Material Motion. Material Design. Mountain View, 2016. Disponível em <https://www.google.com/design/spec/motion/material-motion.html> Acesso em 03/05/2016.

JOHNSON, Steven. Cultura da Interface. Rio de Janeiro: Zahar, 2001.

KRUG, Steve. Don't Make Me Think, Revisited: A Common Sense Approach to Web Usability. São Francisco: New Riders Publishing, 2014.

MAYER, Richard E. Multimedia Learning. 2 ed. Cambridge: Cambridge University Press, 2009.

PRETTO, Nelson de Luca. Globalização \& Organização: Mercado de Trabalho, Tecnologias de Comunicação, Educação a Distância e Sociedade Planetária. ljuí: Editora Unijuí, 1999.

RAMOS, Patrícia Edí. O professor frente às novas tecnologias de informação e comunicação. São José dos Quatro Marcos, 2014. Disponível em <http://www.seduc.mt.gov.br/Paginas/O-professorfrente-\%C3\%A0s-novas-tecnologias-de-informa\%C3\%A7\%C3\%A3o-e-

comunica\%C3\%A7\%C3\%A3o.aspx> Acesso em 16/05/2016.

REATEGUI, Eliseo. Interfaces para Softwares Educativos. Caxias do Sul, 2007. Disponível em <http://www.cinted.ufrgs.br/ciclo9/artigos/eliseo_apres.pdf> Acesso em 04/05/2016.

ROGERS, Yvonne; SHARP, Helen; PREECE, Jennifer. Design de Interação: Além da interação humano-computador. 3 ed. Porto Alegre: Bookman, 2013.

TANENBAUM, Andrew S. Sistemas Operacionais Modernos. 2 ed. São Paulo: Pearson Prentice Hall, 2003. 